\title{
Healthcare utilisation and out-of-pocket expenditure of type 2 diabetes patients with and without comorbidity: A study in primary care in Bhubaneswar, India.
}

\section{Sandipana Pati ( $\sim$ sandipana.pati@gmail.com )}

Public Health Foundation of India https://orcid.org/0000-0001-8989-049X

\section{Subhashisa Swain}

University of Nottingham

Marjan van den Akker

Goethe-Universitat Frankfurt am Main

F. (François) G. Schellevis

Nederlands Instituut voor Onderzoek van de Gezondheidszorg

Jako S. Burgers

Universiteit Maastricht

\section{Research article}

Keywords: type 2 diabetes mellitus, comorbidities, out-of-pocket expenditure, healthcare utilisation

Posted Date: July 6th, 2020

DOI: https://doi.org/10.21203/rs.3.rs-18072/v2

License: (c) (1) This work is licensed under a Creative Commons Attribution 4.0 International License.

Read Full License 


\section{Abstract}

Background: Globally, non-communicable diseases (NCD) demand a higher healthcare expenditure. Amongst the NCDs, diabetes mellitus, is often associated with multiple, co-existing chronic conditions. In low- and middle-income countries where most of the healthcare expenditure is borne out of pocket, diabetes management may pose a significant financial stress.

Methods: A cross-sectional study was conducted in 17 urban primary healthcare facilities of Bhubaneswar to assess the healthcare utilisation and out-of-pocket expenditure among type 2 diabetes patients attending these facilities. Healthcare utilisation was determined by the number of visits to healthcare facilities in the last six months, and out-of-pocket expenditure was assessed by outpatient consultation fees, medicines, travels to health care facilities and diagnostic tests. Total out-of-pocket expenditure was defined as the sum of these costs.

Results: The median number of visits in 6 months for diabetes patients with any comorbidity was 4 and 5 for diabetes patients with more than 4 comorbidities. Among the comorbid conditions, depression, stroke, auditory impairment and acid peptic disease were associated with higher healthcare utilisation. The total out-of-pocket expense was 2.3 times higher among diabetes patients with any comorbid condition compared to patients with diabetes only. The total median expenditure was higher for diabetes patients having stroke, heart diseases, kidney diseases and cancer compared to other comorbid conditions. The association of comorbidity in diabetes patients with health care utilization and out-of-pocket expenditure is statistically significant after adjustment for sociodemographic characteristics and diabetes duration.

Conclusion: Considerable expenditure is incurred by diabetes patients attending primary healthcare facilities for the management of diabetes and other chronic conditions. This is a significant burden for diabetes patients below the poverty line and with limited or no insurance cover. There is a need to increase the coverage of insurance schemes to address the chronic conditions management expenditure of outpatients.

\section{Background}

Type 2 diabetes mellitus (T2DM) is a chronic metabolic disorder associated with morbidity, disability and premature mortality. Diabetes Mellitus (DM) patients frequently suffer from complications and related or unrelated comorbidities. [1,2] The debilitating nature of DM is associated with significant direct and indirect costs for treatment, managing complications and comorbidities. The increased use of healthcare resources with the presence of comorbidities is well established. [3] Struijs et al., for example, have inferred that different comorbid conditions have different effects on healthcare utilization and that diabetes patients with non-vascular comorbidities have similar amount of healthcare needs as those diabetes patients with vascular comorbidities, while diabetes patients without comorbidity use less care compared to those with comorbidity. [4] 
Among low- and middle-income countries (LMIC) like India, where almost two-thirds of healthcare financing is out-of-pocket, diabetes patients face an enormous cost burden. The absence of any cover or minimal insurance policies further amplify their costs and jeopardize their access to the necessary healthcare.[5] Bhojani et al concluded in their study in a poor urban neighbourhood in South India that due to the out-of-pocket spending on their chronic conditions management the number of people living below poverty line were doubled in one month, with further worsening of their poverty.[6] Attaei et al. in their study observed a decline in adherence to medicines with an increase in out-of-pocket expenses, and improved adherence with low out-of-pocket expenditures and enhanced insurance coverage including medicine costs.[7] With a rapidly growing number of diabetes patients in India, the burden of DM on total healthcare expenditure is likely to increase and, potentially, will have important consequences for the sustainability of healthcare.[8] This poses a challenge to the strengthening of the Indian healthcare system and the government's plan to achieve universal health coverage by 2022.[9]

The Rashtriya Swasthya Bima Yojana (RSBY) or National Health Insurance Programme launched by the Indian Ministry of Labour and Employment (currently under the purview of the Department of Health and Family Welfare) [10] to provide insurance coverage for inpatient care to 'Below Poverty Line' families and the unorganized labor force does not cover outpatient care expenses. Past studies have also proved that non-inclusion of expenditure on medicines, laboratory testing and outpatient visits has limited the role of RSBY in mitigating financial risk among the beneficiaries. [11]

Though extensive studies have been carried out in Europe to look into the effects of comorbidity on healthcare expenditure and healthcare utilisation among diabetes patients attending different levels of healthcare, such studies are few and far between in the Indian subcontinent. In LMIC settings where the population still depend on the primary care health facilities for the routine management of their chronic conditions, there is a need to explore the costs related to manage diabetes and comorbidities by diabetes patients. The present study aims to provide an overview of the healthcare utilisation and out-of-pocket expenditure of diabetes patients attending primary health care facilities in Bhubaneswar, India. We examined the impact of comorbidity on healthcare utilisation and costs borne by diabetes patients and the effects of different comorbidities on health care utilisation and out-of-pocket expenditures.

\section{Methods}

\section{Study design and setting}

A cross-sectional interview survey was conducted in all 17 urban primary healthcare centres in Bhubaneswar, the capital city of Odisha with a population of 900,000 inhabitants. [12] The National Sample Survey Office (NSSO) in its report on social consumption of health has indicated that the public healthcare facilities in Odisha provide almost $72 \%$ of outpatient care for the population of the state. [13] The public health care system has a three-tier structure (primary, secondary and tertiary levels). Primary Health Care Centres are involved in delivering primary care while district hospitals and sub-divisional hospitals provide secondary care. Tertiary health care is provided by medical college hospitals. 


\section{Study participants}

The data collection for the present study was conducted between September 2014 and February 2015 at the public primary healthcare facilities. The inclusion criteria for the study was type 2 diabetes patients (diagnosed as type 2 diabetes mellitus by a physician) with a diabetes duration of more than six months. Keeping in consideration the limited consultation hours in the healthcare facilities, every third eligible diabetes patient was approached to participate in the study. The inclusion criterion of at least six months of diabetes duration was applied for the diabetes patients as we needed information about healthcare utilisation for diabetes. The exclusion criteria for the study were severely ill diabetes patients or with acute health problems. Anonymised details of all diabetes patients who were excluded (age, gender, reason for exclusion) from the study, were recorded to compare the characteristics of the participants with the non-participants.

\section{Measurements}

The participants of the study were interviewed in a separate private room in the primarycare facility using a predesigned and pretested questionnaire, Diabetes Co-morbidity Evaluation Tool in Primary Care (DCET$P C)$. The DCET-PC is derived from "Multimorbidity Assessment Questionnaire for Primary Care", a validated questionnaire which was pretested and the feedback used to adapt the questionnaire for our study. [14] Two graduate nurses trained in patient history-taking and interview techniques carried out the interviews, and $10 \%$ of the interviews were done in the presence of the first author. The DCET-PC (Appendix 1) included questions about the existence of comorbid conditions, eliciting information on whether the patient had any of the 16 listed chronic conditions, and socio-demographic details, i.e. age, sex, residence (rural, semi-urban, urban), ethnicity (general, scheduled caste and tribe, other backward classes), religion (Hindu, Muslim, Christian, others), educational level (no education, primary level, secondary, graduate and above), marital status (single, married), annual family income (categorised into five quintiles) and household status (above poverty line, below poverty line). The details of development and domains of the DCET-PC questionnaire were described in our previous paper. [1]

We estimated comorbidity in three ways: 1) presence or absence of any comorbidity, which was further categorised into 2) the number of comorbid conditions (zero, one, two, three, four or more chronic conditions), and 3 ) the presence of any one of the 15 chronic conditions (hypertension, acid peptic disease, back pain, arthritis, lung disease, visual impairment, auditory impairment, heart disease, stroke, kidney disease, epilepsy, cancer, thyroid disorder, obesity, depression) in our study in one individual patient. Healthcare utilisation was operationalized as the reported number of visits to any healthcare facility in the last six months for any reason. Out-of-pocket expenditure was measured in Indian Rupees (INR) by asking about expenses incurred in the last six months separately for outpatient consultation fees, medicines (for DM and other diseases separately), travelling to those healthcare facilities, and diagnostic tests (for DM and other diseases separately). Total out-of-pocket expenditure was defined as the sum of these costs.

\section{Analysis}


To estimate the healthcare utilization, due to the skewed natured of the data, median (interquartile ranges) number of visits done by the patient to any healthcare facility during last six months were calculated. Healthcare utilization and out-of-pocket expenditure were further described across the number of comorbid conditions and the prevalence of leading comorbidities. Bivariate comparison was performed using a Kruskal Wallis test for quantitative data (on the basis of median values) and a chisquare test for categorical data. Furthermore, we calculated the median and interquartile ranges of out-ofpocket expenditure by comorbidity status ( $\mathrm{Yes} / \mathrm{No}$ ). The difference in mean out-of-pocket expenditure and healthcare utilization across the comorbidity groups was tested using Wilcoxson signed rank test.

Poisson regression model in multilevel mixed effects methods was used with two levels (health center and patient) for multivariate analysis to assess the independent contribution of comorbidity on healthcare utilization and out-of-pocket expenditure. The collinearity between the variables was tested before including them in multivariate analysis. Adjusted incidence rate ratio was calculated for each predictor for estimating health care utilization and expenditure. A p-value of $<0.05$ was considered statistically significant. Analyses were performed in STATA Corp-12 Tx.

\section{Results}

\section{Participants}

We approached 942 diabetes patients, of whom 912 (97\%) consented to be interviewed. The reasons cited for not participating were lack of time and unwillingness to answer. Of all respondents, 575 [63\%] were male. The highest number of respondents was in the age group 40-69 years ( $N=766$ [83\%]). The mean age of the respondents was 55 years. The mean number of health facility visits was 7.1 [SD: 11.7]. The mean total healthcare expenditure was INR 2,653 [SD 2,975]. Nearly $84 \%$ of patients had comorbidity, $29 \%$ had a single comorbidity, $25 \%$ had two comorbidities, $17 \%$ reported having three, and $14 \%$ had four or more comorbidities [Table 1].

\section{Health care utilisation}

The median number of visits of diabetes patients without any comorbidity in 6 months was $5(\mathrm{IQR}=5)$ and $4(\mathrm{IQR}=4)$ for patients having any comorbidity and $5(\mathrm{IQR}=5)$ for diabetes patients with four or more comorbidities. [Table 2]. Among diabetes patients with comorbidity the median number of visits was highest for patients with depression $6(\mathrm{IQR}=4)$, acid peptic disease (APD) $6(\mathrm{IQR}=5)$, auditory impairment/deafness $6(\mathrm{IQR}=5)$, stroke $6(\mathrm{IQR}=17)$, followed by thyroid disease $4.5(\mathrm{IQR}=5)$ cancer 4.5 $(\mathrm{IQR}=5)$ and visual impairment/blindness $4(\mathrm{IQR}=5)$ [Table 4].

\section{Out-of-pocket expenditure}

We found a linear increase in total expenditure along with costs for medicines on diabetes, medicines for other diseases, and laboratory testing for other diseases with the number of comorbidities, which was statistically significant [Table 3]. No significant association was found between expenditures for travels 
to hospital and laboratory investigation for diabetes, and the number of comorbid conditions. Patients with any comorbidity spent two times more compared to those having no comorbidity. Diabetes patients with any comorbid condition had a two times higher expenditure for medicines (for diabetes and comorbidity) than patients with only diabetes. Among diabetes patients having one chronic condition the median total expenditure ranged from 1,565 INR to 4,220 INR. The total median expenditure was higher for patients having stroke, heart diseases, kidney diseases and cancer compared to other comorbid conditions [Table 3].

\section{Multivariate analyses}

Multivariate adjusted multilevel mixed effect Poisson regression analyses showed a strong positive association of diabetes patients with comorbidities with healthcare utilisation [RR 1.33; 95\% Cl 1.24-1.43] and out of pocket expenditure. [RR 1.97; 95\% $\mathrm{Cl} 1.96-1.98$ ] [Table 4] compared to diabetes patients without comorbidity.

\section{Discussion}

The present study assessed the healthcare utilization and out-of-pocket expenditure among diabetes patients with and without comorbidities attending primary healthcare centres in India. Our study indicates the substantially larger number of visits to healthcare facilities among diabetes patients with comorbidity compared to those without comorbidity, which is similar to findings of prior studies outside India. $[4,15]$ We also found that the largest proportion of the total out-of-pocket expenditure went on medicines. Sum et al. have also concluded in their study on multimorbidity and out-of-pocket expenditure that the costs of medicines contributed to a substantial share of total expenditure. [16] Another major finding of our study is that diabetes patients with any additional comorbidity had increased total out-of-pocket expenditure along with costs for medicines for diabetes, medicines for other diseases, and laboratory testing for other diseases. This expenditure increased with the number of comorbidities. The other finding of our study that diabetes patients above poverty line had a higher prevalence of comorbid conditions in comparison to diabetes patients from below poverty line is divergent from study findings from developed countries but similar to findings from studies conducted in India. [17,18]

Wang et al. in their study have also concluded that the number of visits to health facilities increased with increase in number of complications associated with diabetes. [3] Likewise, Grunier et al concluded that rise in the number of comorbid conditions raised the healthcare utilisation among diabetes patients. [19] Our study finding of higher healthcare utilisation among diabetes patients with comorbid conditions like APD, stroke, deafness and depression is similar to findings from other studies. [20,21]

Our finding of increase in expenditure due to comorbid conditions among diabetes patients is consistent with the results from previous studies in middle- and low-income countries.[23,24,25] Thakrar et al. concluded that the presence of an additional comorbid condition further enhances the cost burden among diabetes patients.[26] Similarly, Akari et al. analyzed the healthcare costs by calculating the direct and indirect costs of diabetes with comorbidities among hospitalized patients in a tertiary care hospital 
and concluded that higher expenses were incurred by diabetes patients with three or more comorbidities and also those with macro-vascular complications.[27] Acharya et al. assessed the costs of illness for diabetes patients with or without complications hospitalized in a tertiary care hospital; they concluded that diabetes patients with renal and cardiac complications incurred greater expenses than those with other chronic complications. [28] These studies only investigated the cost of concordant comorbidities and complications associated with diabetes. As our study has taken into account both concordant and discordant comorbidities, comparability to these studies is limited. Piette and Kerr classified comorbid conditions as concordant or discordant and concluded that concordant conditions resulted in better diabetes care but the clinically dominant condition may lead to worse diabetes management. [29] Other studies from developed countries have also reported findings similar to the present study. [30,31]

\section{Strengths And Limitations}

This is the first study in India assessing the healthcare utilisation and out-of-pocket expenditure among diabetes patients attending primary health care facilities and also taking a wide range of comorbidities into account, i.e. both concordant and discordant comorbid conditions. The findings are generally representative of urban primary healthcare users in India.

Self-reported comorbidity status as reported by the patients is one of our study limitations. Patients who had not been diagnosed or had conditions which were not reported were not included. The exclusion of undiagnosed type 2 diabetes mellitus patients is the other limitation of this study. As it is a crosssectional study, it shows associations but not causal relations.

\section{Conclusion}

The findings of our study bring forth the high expenditure incurred by diabetes patients with certain comorbidity patterns. In LMIC settings where most of the diabetes patients have limited resources, the understanding of these patterns of comorbid conditions can prove useful in guiding the primary care physicians in setting up treatment priorities and designing cost effective treatment strategies. Similarly, higher healthcare utilisation has been found among diabetes patients with specific comorbidities. A more detailed study of factors of the healthcare utilisation could help in designing interventions to minimize the avoidable visits and reduce the dependence on the healthcare facilities. Some of the interventions like increased household visits by trained community level health workers and teleconsultation of the diabetes patients with the primary care physicians could enhance self-management practices among diabetes patients, resulting in fewer visits to health facilities and thus lessening the burden on primary health facilities and physicians. Zulman et al in their study on comorbidity interrelatedness have highlighted the importance of comorbidity interrelatedness or clinical complexity and its effect on the quality of care. [32] Our findings of high costs and healthcare utilisation for specific comorbid conditions could also form a base for future study into the economic impact of comorbidity interrelatedness and solutions for affordable management of multiple chronic conditions. 
The draft of India`s National Health Policy [33] states that 63 million people have been pushed into poverty due to out-of-pocket expenditure on healthcare. As India progresses towards Universal Health Coverage, the financial burden posed by comorbidity among diabetes patients needs to be considered in greater detail. The ICMR INDIAB study on diabetes by Anjana and colleagues have also confirmed the high prevalence of diabetes among the low socioeconomic sections in the urban areas. In the light of the findings of our study, this reiterates the need for a more comprehensive and robust policy to address outof-pocket expenditures. [34] It is important to explore the various components of out of pocket expenditure and identify the components with maximum cost impact like medications, laboratory investigations or visit to numerous centres for management of different comorbid conditions. The indirect expenses like loss of wages and disability adjusted life years (DALY) should also be studied. Collecting data on glycated haemoglobin ( $\mathrm{HbA} 1 \mathrm{c})$ could help in studying the impact of glycaemic control and healthcare utilisation and out-of-pocket expenditure.

The present study indicates higher healthcare utilization among diabetes patients with comorbid depression. With the government of India's thrust to expand the National Mental Health Programme, [35] the provision of mental health counselors at the primary care level could go a long way towards better management. As our study suggests that diabetes patients with comorbidities incur considerable out-ofpocket expenses, even in public primary care facilities, it can be expected that the expenses will be higher in private healthcare facilities. Hence, increased insurance coverage that includes outpatient services would help in alleviating the expenditure burden.

\section{Declarations}

\section{Ethics approval and consent to participate}

Respondents were informed about the purpose of the study and the information used. We collected their signature or thumb impression on the informed consent form. The data were coded, and the identities of the respondents were kept confidential. The Odisha state research and ethics committee granted ethical approval for the study (letter no. 161/SHRMU dated 16/05/2014).

\section{Consent for publication}

Not applicable

\section{Availability of data and materials}

The data is available with the corresponding author, and can be made available on reasonable request and permission from State human resources management unit, Department of Health and Family Welfare, government of Odisha.

\section{Competing interests}

The authors declare they have no competing interests. 


\section{Funding}

No external funding was received.

\section{Authors contribution}

SP and FGS have designed the study, SS has analyzed the data, MA and JB have interpreted the findings. All the authors have contributed to the writing of the manuscript. All authors read and approved the final manuscript.

\section{Acknowledgements}

The authors are grateful to all the participants of the present study and the department of Health and Family Welfare, Government of Odisha.

\section{Abbreviations}

NCD: Non-communicable disease

T2DM: Type 2 diabetes mellitus

DM: Diabetes mellitus

LMIC: Low and middle income countries

RSBY: Rashtriya Swasthya Bima Yojana

DCET-PC: Diabetes Co-morbidity Evaluation Tool in Primary Care

APD: Acid Peptic Disease

DALY: Disability adjusted life years

\section{References}

1. Pati S, Schellevis FG. Prevalence and Pattern of co morbidity among type 2 diabetics attending Urban Public Health Centers at Bhubaneswar (India).PlosOne 2017;12:e0181661.

2. Png ME, Yoong J, Phan TP, Wee HL. Current and future economic burden of diabetes among workingage adults in Asia: conservative estimates for Singapore from 2010-2050. BMC Public Health 2016;;16:153.

3. Wang W, Fu C, Zhuo H, et al. Factors affecting costs and utilization of type 2 diabetes healthcare: a cross-sectional survey among 15 hospitals in urban China. BMC Health Services Research. 2010;10:244. 
4. Struijs JN, Baan CA, Schellevis FG, et al. Comorbidity in patients with diabetes mellitus: impact on medical health care utilization. BMC Health Services Research. 2006;6:84.

5. Kapur A. Influence of socio-economic factors on diabetes care. Int J Diab Dev Countries.2001;21:7785.

6. Bhojani U, Thriveni BS, Devadasan R, et al. Out-of-pocket healthcare payments on chronic conditions impoverish urban poor in Bangalore, India. BMC Public Health. $2012 ; 12: 990$.

7. Attaei MW, Khatib R, McKee M, et al. Availability and affordability of blood pressure-lowering medicines and the effect on blood pressure control in high-income, middle-income, and low-income countries: an analysis of the PURE study data. The Lancet Public Health. 2017 Sep 30;2(9):e411-9.

8. Yesudian CA, Grepstad M, Visintin E, et al. The economic burden of diabetes in India: a review of the literature. Globalization and Health. 2014 ;10: 80.

9. National Health Accounts Estimates for India, 2013-14.Ministry of Health \& Family Welfare, Government of India.www.mohfw.nic.in/sites/default/files/89498311221471416058.pdf. (Accessed on 20th June 2018)

10. RashtriyaSwasthyaBimaYojana, Ministry of Health \& Family Welfare, Government of India. https://www.india.gov.in/spotlight/rashtriya-swasthya-bima-yojana. (Accessed on30th July 2018).

11. Karan A, Yip W, Mahal A. Extending health insurance to the poor in India: An impact evaluation of Rashtriya Swasthya Bima Yojana on out of pocket spending for healthcare. Social Science \& Medicine. 2017 May 1;181:83-92.

12. http://www.censusindia.gov.in/pca/SearchDetails.aspx?ld=456551. Accessed on $7^{\text {th }}$ July 2018.

13. Sundararaman T, Muraleedharan VR, Mukhopadhyay I. NSSO 71st round data on health and beyond. Economic \& Political Weekly. 2016 Jan 16;51(3):85.

14. Pati S, Hussain MA, Swain S, et al. Development and validation of a questionnaire to assess multimorbidity in primary care: An Indian experience. Biomed Res Int. 2016;2016.

15. van Oostrom SH, Picavet HS, de Bruin SR, et al. Multimorbidity of chronic diseases and health care utilization in general practice. BMC Family Practice. $2014 ; 15: 61$

16. Sum G, Hone T, Atun R,et al. Multimorbidity and out-of-pocket expenditure on medicines: a systematic review. BMJ global health. 2018 Feb 1;3(1):e000505.

17. Pati S, Swain S, Hussain MA, Kadam S, Salisbury C. Prevalence, correlates, and outcomes of multimorbidity among patients attending primary care in Odisha, India. The Annals of Family Medicine. 2015 Sep 1;13(5):446-50.

18. Barnett K, Mercer SW, Norbury M, Watt G, Wyke S, Guthrie B. Epidemiology of multimorbidity and implications for health care, research, and medical education: a cross-sectional study. The Lancet. 2012 Jul 7;380(9836):37-43.

19. Gruneir A, Markle-Reid M, Fisher K, et al. Comorbidity burden and health services use in communityliving older adults with diabetes mellitus: a retrospective cohort study. Can. J. Diabetes. 2016 ;40(1):35-42. 
20. Egede LE, Zheng D, Simpson K. Comorbid depression is associated with increased health care use and expenditures in individuals with diabetes. Diabetes Care. 2002 ;25(3):464-70.

21. Calderón-Larrañaga A, Abad-Díez JM, Gimeno-Feliu LA, et al. Global health care use by patients with type-2 diabetes: Does the type of comorbidity matter? European Journal of Internal Medicine. 2015 ;26(3):203-10.

22. Fisher K, Griffith L, Gruneir A, et al. Comorbidity and its relationship with health service use and cost in community-living older adults with diabetes: A population-based study in Ontario, Canada. Diabetes Research and Clinical Practice. 2016 ;122:113-23.

23. Khowaja LA, Khuwaja AK, Cosgrove P. Cost of diabetes care in out-patient clinics of Karachi, Pakistan. BMC Health Services Research.2007;7(1):189.

24. Kumar S, Arya AK, Tripathi R, et al. Cost Burden of Treatment in Type 2 Diabetes Mellitus Patients With and Without Complications: A Population Based Socioeconomic Study in North India. International Journal of Contemporary Medical Research. 2015;2(3):729-34.

25. Al-Maskari F, El-Sadig M, Nagelkerke N. Assessment of the direct medical costs of diabetes mellitus and its complications in the United Arab Emirates. BMC Public Health. 2010;10(1):679.

26. Tharkar S, Satyavani K, Viswanathan V. Cost of medical care among type 2 diabetic patients with a co-morbid condition-Hypertension in India. Diabetes Research and Clinical Practice.2009;83(2):2637.

27. Akari S, Mateti U V, Kunduru B R. Health-care cost of diabetes in South India: A cost of illness study. Journal of Research in Pharmacy Practice. 2013;2:114-117.

28. Acharya LD, Rau NR, Udupa N, et al. Assessment of cost of illness for diabetic patients in South Indian tertiary care hospital. Journal of Pharmacy \&Bioallied sciences. 2016;8:314.

29. Piette JD, Kerr EA. The impact of comorbid chronic conditions on diabetes care. Diabetes care. 2006;29:725-31. PMID: 16505540.

30. O'Shea M, Teeling M, Bennett K. The prevalence and ingredient cost of chronic comorbidity in the Irish elderly population with medication treated type 2 diabetes: a retrospective cross-sectional study using a national pharmacy claims database. BMC Health Services Research. 2013;13(1):23.

31. Norlund A, Apelqvist J, Bitzén PO, et al. Cost of illness of adult diabetes mellitus underestimated if comorbidity is not considered. Journal of Internal Medicine. 2001;250(1):57-65.

32. Zulman DM, Asch SM, Martins SB, Kerr EA, Hoffman BB, Goldstein MK. Quality of care for patients with multiple chronic conditions: the role of comorbidity interrelatedness. Journal of general internal medicine. 2014 Mar;29(3):529-37.

33. Lahariya C. 'Ayushman Bharat'program and universal health coverage in India. Indian pediatrics. 2018 Jun 1;55(6):495-506.

34. Anjana RM, Deepa M, Pradeepa R, et al. A. Prevalence of diabetes and prediabetes in 15 states of India: results from the ICMR-INDIAB population-based cross-sectional study. The Lancet Diabetes \& Endocrinology. 2017;5(8):585-96. 
35. https://www.nhp.gov.in/national-mental-health-programme_pg (Accessed on 15th February 2020)

\section{Tables}

Table 1 Basic characteristics of type 2 diabetes patients by comorbidity status $(n=912)$ 


\begin{tabular}{|c|c|c|}
\hline & $\begin{array}{l}\text { Without co morbidity }(\mathrm{n}=146) \\
\%[95 \% \mathrm{CI}]\end{array}$ & $\begin{array}{l}\text { With co morbidity }(\mathrm{n}=766) \\
\%[95 \% \mathrm{CI}]\end{array}$ \\
\hline \multicolumn{3}{|l|}{ Age group (years) } \\
\hline $18-29$ & $1.3[0.0-3.2]$ & $0.1[0.0-0.4]$ \\
\hline $30-39$ & $8.7[4.1-13.2]$ & $6.3[4.5-8.0]$ \\
\hline $40-49$ & $28.7[21.4-35.9]$ & $20.3[17.4-23.1]$ \\
\hline $50-59$ & $39.3[31.5-47.2]$ & $33.4[30.1-36.7]$ \\
\hline $60-69$ & $17.3[11.2-23.4]$ & $29.5[26.2-32.7]$ \\
\hline$>=70$ & $4.7[1.3-8.1]$ & $10.5[8.3-12.6]$ \\
\hline \multicolumn{3}{|l|}{ Gender } \\
\hline Male & $74.0[66.9-81.1]$ & $61.0[57.5-64.5]$ \\
\hline Female & $26.0[18.9-33.1]$ & $39.0[35.5-42.5]$ \\
\hline \multicolumn{3}{|l|}{ Place of residence } \\
\hline Urban & $76.0[69.1-82.9]$ & $78.4[75.5-81.3]$ \\
\hline Semi Urban & 8.7[4.1-13.2] & $11.4[9.1-13.6]$ \\
\hline Rural & $15.3[9.5-21.1]$ & $10.2[8.0-12.4]$ \\
\hline \multicolumn{3}{|l|}{ Ethnicity } \\
\hline Schedule Caste & $14.7[8.9-20.3]$ & $31.5[28.2-34.8]$ \\
\hline Schedule Tribe & $5.3[1.7-8.9]$ & $13.1[10.7-15.5]$ \\
\hline Other Backward Caste & $22.7[15.9-29.4]$ & $12.6[10.2-14.9]$ \\
\hline Others & $57.3[49.4-65.3]$ & $42.8[39.3-46.3]$ \\
\hline \multicolumn{3}{|l|}{ Socio-economic status } \\
\hline Above Poverty Line & $36.2[24.8-47.7]$ & $70.5[66.4-74.6]$ \\
\hline Below Poverty Line & $63.8[52.3-75.2]$ & $29.5[25.4-33.6]$ \\
\hline \multicolumn{3}{|l|}{ Highest Education } \\
\hline Illiterate & $8.7[4.1-13.2]$ & $8.4[6.4-10.3]$ \\
\hline Primary & $22.0[15.3-28.7]$ & $16.0[13.4-18.6]$ \\
\hline Secondary & $32.7[25.1-40.2]$ & $34.8[31.4-38.2]$ \\
\hline University & $36.7[28.9-44.4]$ & $40.8[37.3-38.2]$ \\
\hline \multicolumn{3}{|l|}{ Marital Status } \\
\hline Single & $13.2[10.8-15.6]$ & $8.7[4.1-13.2]$ \\
\hline Married & $86.8[84.4-89.2]$ & $91.3[86.8-95.5]$ \\
\hline
\end{tabular}




\begin{tabular}{|c|c|c|}
\hline \multicolumn{3}{|l|}{ Religion } \\
\hline Hindu & $92.0[87.6-96.4]$ & $88.4[86.1-90.6]$ \\
\hline Other & $8.0[6.6-12.4]$ & $11.6[9.4-13.9]$ \\
\hline \multicolumn{3}{|c|}{ Family history of diabetes mellitus } \\
\hline Yes & $10.7[5.7-15.6]$ & $24.7[21.7-27.8]$ \\
\hline No & $89.3[84.4-94.3]$ & $75.3[72.2-78.3]$ \\
\hline \multicolumn{3}{|l|}{ Risk Factor: BMI } \\
\hline Underweight & $4.7[1.3-8.1]$ & $2.1[1.1-3.1]$ \\
\hline Normal & $40.0[32.1-47.9]$ & $20.0[17.2-22.9]$ \\
\hline Overweight & $19.3[13.0-25.7]$ & $19.4[16.5-22.2]$ \\
\hline Obese & $36.0[28.3-43.7]$ & $58.5[55.0-62.0]$ \\
\hline \multicolumn{3}{|c|}{ Health facility visits in last 6 months } \\
\hline Never & $2.0[0.1-4.2]$ & $1.0[0.3-1.8]$ \\
\hline $1-2$ visits & $26.7[19.5-33.8]$ & $16.7[14.1-19.4]$ \\
\hline 3-4 visits & $20.0[13.6-26.4]$ & $36.4[32.9-39.8]$ \\
\hline $5-6$ visits & $24.7[17.7-31.6]$ & $20.1[17.2-22.9]$ \\
\hline $7-8$ visits & $15.3[9.5-21.1]$ & $12.4[10.1-14.8]$ \\
\hline 9 or more visits & $11.3[6.2-16.4]$ & $13.3[11.0-15.8]$ \\
\hline \multicolumn{3}{|c|}{ Total expenditure } \\
\hline$<=1000$ INR & $48.1[39.9-56.0]$ & $18.9[16.1-21.6]$ \\
\hline 1001-2000 INR & $35.3[27.6-43.0]$ & $30.6[27.3-33.9]$ \\
\hline 2001-3000 INR & $9.3[4.6-14.0]$ & $19.8[16.9-22.6]$ \\
\hline > 3000 INR & $7.3[3.1-11.5]$ & $30.7[27.5-34.0]$ \\
\hline
\end{tabular}

Table 2 Healthcare utilization by number of comorbidities: median number and range. 


\begin{tabular}{cl}
\hline Number of comorbidities & $\begin{array}{l}\text { Number of visits to health facility in last } 6 \text { months } \\
\text { Median (Range) }\end{array}$ \\
\hline Zero & $5(0-55)$ \\
1 & $4(0-56)$ \\
2 & $4(0-59)$ \\
3 & $4(0-46)$ \\
$>=4$ & $5(0-57)$ \\
Total & $4(0-59)$ \\
Diabetes with any Comorbidity & $4(0-59)$ \\
\hline Kruskal Wallis, F (P value) & $\mathrm{F}=0.707,\left(\mathrm{p}=0.587 \_\right)$ \\
\hline
\end{tabular}

Table-3 Out of pocket expenditure by number of comorbidities (median INR).

\begin{tabular}{|c|c|c|c|c|c|c|}
\hline $\begin{array}{l}\text { Number of } \\
\text { comorbidities }\end{array}$ & $\begin{array}{l}\text { Medicine } \\
\text { Diabetes } \\
\text { (median } \\
\text { INR) }\end{array}$ & $\begin{array}{l}\text { Medicine } \\
\text { Other } \\
\text { disease } \\
\text { (median } \\
\text { INR) }\end{array}$ & $\begin{array}{l}\text { Travel to } \\
\text { Hospital } \\
\text { (median } \\
\text { INR) }\end{array}$ & $\begin{array}{l}\text { Test Cost } \\
\text { for } \\
\text { Diabetes } \\
\text { (median } \\
\text { INR) }\end{array}$ & $\begin{array}{l}\text { Test Cost } \\
\text { for Other } \\
\text { diseases } \\
\text { (median } \\
\text { INR) }\end{array}$ & $\begin{array}{l}\text { Total } \\
\text { Expenditure } \\
\text { (median } \\
\text { INR) }\end{array}$ \\
\hline & & & & & & \\
\hline Zero & 500 & 0 & 50 & 300 & 0 & 1045 \\
\hline 1 & 600 & 200 & 50 & 332 & 0 & 1400 \\
\hline 2 & 800 & 500 & 40 & 300 & 0 & 2000 \\
\hline 3 & 1000 & 500 & 40 & 300 & 200 & 2460 \\
\hline$>=4$ & 1000 & 1000 & 5 & 400 & 400 & 3110 \\
\hline $\begin{array}{l}\text { Diabetes with } \\
\text { any } \\
\text { comorbidity }\end{array}$ & 800 & 440 & 40 & 300 & 100 & 2030 \\
\hline $\begin{array}{l}\text { Kruskal-Wallis } \\
\text { test }(\mathrm{F})\end{array}$ & $\begin{array}{l}11.14 \\
p<0.001\end{array}$ & $\begin{array}{l}11.31, \\
p<0.001\end{array}$ & $\begin{array}{l}0.80, \\
p=0.524\end{array}$ & $\begin{array}{l}1.94 \\
P=0.102\end{array}$ & $\begin{array}{l}13.42, \\
p<0.001\end{array}$ & $\begin{array}{l}14.21 \\
\mathrm{p}<0.001\end{array}$ \\
\hline
\end{tabular}

Table- 4 Healthcare utilisation and Out of pocket expenditure across comorbid condition. 


\begin{tabular}{|c|c|c|}
\hline Conditions Combinations & $\begin{array}{l}\text { Number of visits in last } \\
6 \text { months } \\
\text { Median(Range) }\end{array}$ & $\begin{array}{l}\text { Total expenditure (In INR) } \\
\text { Median (Range) }\end{array}$ \\
\hline DM+ Hypertension $(n=181)$ & $4(0-53)$ & $2100(115-25700)$ \\
\hline $\begin{array}{l}\text { DM+ Acid Peptic } \\
\text { Disease }(\mathrm{n}=74)\end{array}$ & $6(0-59)$ & $1630(115-25700)$ \\
\hline $\mathrm{DM}+$ Obesity $(\mathrm{n}=54)$ & $4(0-55)$ & $870(0-9100)$ \\
\hline DM+ Backpain $(\mathrm{n}=48)$ & $4(1-44)$ & $2000(450-7200)$ \\
\hline DM+ Arthritis $(n=39)$ & $3.5(0-59)$ & $1715(550-7200)$ \\
\hline $\begin{array}{l}\text { DM+ Visual } \\
\text { impairment/Blindness }(n=25)\end{array}$ & $4(2-53)$ & $1930(280-5990)$ \\
\hline DM+ Thyroid $(n=22)$ & $4.5(2-59)$ & $1980(350-10150)$ \\
\hline $\mathrm{DM}+$ Lung Disease $(\mathrm{n}=16)$ & $4(2-12)$ & $2030(410-6900)$ \\
\hline DM+ Heart Disease $(n=13)$ & $4(2-52)$ & $3600(2600-16100)$ \\
\hline DM+ Stroke $(n=7)$ & $6(3-39)$ & $4220(800-10150)$ \\
\hline DM+ Kidney Disease $(n=6)$ & $4(2-9)$ & $3168(1740-18100)$ \\
\hline DM+ Epilepsy $(n=6)$ & $3.5(1-5)$ & $1565(350-2130)$ \\
\hline DM+ Cancer $(n=6)$ & $4.5(2-8)$ & $2685(1210-6020)$ \\
\hline DM+ Deafness $(n=5)$ & $6(2-8)$ & $2480(1200-21000)$ \\
\hline DM+ Depression $(n=3)$ & $6(4-8)$ & $1860(1300-2020)$ \\
\hline
\end{tabular}

DM: Diabetes Mellitus

Table 5- Predictors of Healthcare utilization and total out-of-pocket expenditure of diabetes patients ( $\mathrm{N}=912)$ using multilevel mixed effect Poisson modelling; unadjusted and adjusted rate ratios $(\mathrm{RR})$ and $95 \%$ Confidence Intervals $(95 \% \mathrm{CI})$ 


\begin{tabular}{|l|c|c|c|c|c|}
\hline & & \multicolumn{2}{|c|}{ Healthcare utilisation } & \multicolumn{2}{c|}{ Total Expenditure } \\
\hline Variables & Categories & Unadjusted & Adjusted RR \\
& & RR & Unadjusted \\
RR & Adjusted \\
& & {$[95 \% \mathrm{CI}]$} & $\mathrm{RR}^{\#}$ \\
& & & & {$[95 \% \mathrm{CI}]$} & {$[95 \% \mathrm{CI}]$} \\
\hline Comorbidity & Only Diabetes & Reference & Reference & Reference & Reference \\
\hline & DM with & $1.31[1.22-$ & $1.33[1.24-$ & $2.20[2.19-$ & $1.97[1.96-$ \\
& Comorbidity & $1.40]^{*}$ & $1.43] *$ & $2.21] *$ & $1.98] *$ \\
\hline
\end{tabular}

\# adjusted for patient characteristics (diabetes duration, age, sex, educational status, income and marital status), *P value $<0.05$ 